\title{
Parâmetros de qualidade do leite de cabra armazenado sob frio
}

\section{Effects of cold storage on the quality parameters of goat milk}

\author{
Carina Morais Correa Dutra ${ }^{1}$, Bianca Svierk², Maria Edi da Rocha Ribeiro ${ }^{3}$, \\ Andrea Troller Pinto ${ }^{2}$, Maira Balbinotti Zanela ${ }^{3}$, Verônica Schmidt ${ }^{2 *}$
}

RESUMO: O leite de cabra é produzido em pequena escala, o que torna necessária sua estocagem, permitida pela legislação brasileira. O presente trabalho teve por objetivo avaliar a açáo do resfriamento e congelamento sobre as características físico-químicas e microbiológicas do leite de cabra. Não foi observada variabilidade nos valores médios de acidez, estabilidade ao álcool, densidade, gordura, proteína, sólidos totais e lactose após armazenamento sob frio. Não foi observada instabilidade ao calor em nenhuma das amostras analisadas. Verificou-se tendência à diminuição na contagem de células somáticas (CSS) no leite congelado em relação ao fresco e ao refrigerado. A quantificação (NMP) de coliformes totais e termotolerantes variou de $<3$ (ausência de crescimento) à $>1.100 \mathrm{UFC} / \mathrm{mL}$, independentemente do armazenamento. Entretanto, determinou-se contagem de coliformes totais e termotolerantes significativamente maior $(\mathrm{p}<0,0001)$ nas amostras mantidas sob refrigeração. Na prova de lactofermentação, observaram-se coágulos digeridos, floculosos e sulcados sem estabelecer correlação entre estes e a contagem bacteriana. A CCS e a contagem microbiana são critérios adotados no pagamento pela qualidade no leite caprino, e a temperatura de armazenamento pode influir sobre elas.

PALAVRAS-CHAVE: leite de cabra; composição; temperatura de conservação; indicadores bacterianos; refrigeração; congelação.

\begin{abstract}
The small-scale goat milk production requires its storage, and such operation is allowed by Brazilian laws. This study aimed at evaluating the cooling and freezing effects on physical-chemical and microbiological characteristics of goat milk. However, no variability was verified in average acidity, alcohol stability, density, fat protein, total solids and lactose values after cold storage. Heat instability was not observed in any of the analyzed samples. There was a decreasing tendency in the somatic cell count (SCC) of frozen milk in comparison to fresh and refrigerated milk. The quantification (NMP) of total and thermo-tolerant coliforms varies from $<3$ (no growth) to $>1,100 \mathrm{UFC} / \mathrm{mL}$, regardless of the storage method. However, a slightly higher count $(\mathrm{p}<0.0001)$ was observed for total and thermo-tolerant coliforms in the samples kept under refrigeration. In the lactofermentation test, digested, flocculated and grooved clots were observed without establishing a correlation between them and the bacterial count. SCC and microbial count are the criteria adopted when paying for the quality of goat milk, and the storage temperature may affect these criteria.
\end{abstract}

KEYWORDS: goat milk; composition; storage temperature; bacterial indicators; refrigeration; freezing. 


\section{INTRODUÇÃO}

O Brasil é o maior produtor de leite de cabra da América do Sul, com cerca de 148.000 toneladas/ano (FAO, 2011). Esta produção está concentrada principalmente nos estados das regióes nordeste, sul e sudeste, em mais de 18 mil estabelecimentos, sendo que cerca de mil desses estabelecimentos encontram-se na regiáo Sul (IBGE, 2006).

A produção de leite é uma atividade cada vez mais competitiva e, portanto, é importante quantificar e qualificar os fatores que podem influenciá-la, buscando ganhos efetivos na quantidade e na qualidade do leite produzido na tentativa de suprir a demanda nacional (Coldebella et al., 2004).

$\mathrm{O}$ atendimento a parâmetros de qualidade, como teor de gordura e sólidos totais, vem sendo utilizado para o pagamento do leite por qualidade na cadeia láctea bovina há bastante tempo. $\mathrm{Na}$ cadeia láctea caprina, esta prática também vem sendo introduzida pelas indústrias beneficiadoras. A qualidade do leite envolve a composição e as condições sanitárias, mas, no Brasil, os programas considerados de "pagamento por qualidade" geralmente incluem uma série de fatores relacionados às condiçóes de produção. Porém, estas não medem a qualidade em si, como o volume, a sazonalidade, a infraestrutura, o manejo, a raça do reprodutor, os cuidados sanitários, entre outros (MADALENA, 2000).

Considerando o volume diário de leite caprino produzido, a coleta pela indústria beneficiadora ocorre em períodos que variam de dois a sete dias. Para a conservação do leite sob baixa temperatura, utilizam-se os processos de refrigeração e congelação (Evangelista, 1987), uma vez que a legislação brasileira (BrASIL, 2000) permite o congelamento do leite da espécie caprina nos estabelecimentos produtores.

Os programas de qualidade do leite têm como objetivo assegurar que as qualidades nutricionais, sabor e aparência originais do leite sejam preservados, e que micro-organismos nocivos ou adulterantes não estejam presentes (Рнгцрот, 1998). O programa de pagamento por qualidade do leite de cabra teve início na França, em função da qualidade química (concentração média de gordura e proteínas) e microbiológica (Le Mens, 1991). Posteriormente, outros países da Europa (Portugal, Espanha, Itália, Grécia, Noruega e Holanda), Estados Unidos, Canadá, Israel e Taiwan implantaram sistemas de pagamento por qualidade para o leite de cabra (PIrisi et al., 2007).

A qualidade do leite que chega à indústria de processamento é determinada pelo leite que sai da propriedade, sendo que os processadores não podem melhorar a qualidade do leite cru que recebem (Рніцpot, 1998). Estudos demonstram a adequação tecnológica e sensorial de queijos produzidos a partir de leite armazenado congelado (CURI; BonAssi, 2007); entretanto, pouco se sabe sobre o efeito deste processo na qualidade do leite caprino. Nesse sentido, o objetivo do presente estudo foi determinar o efeito do resfriamento prolongado e do congelamento sobre parâmetros de qualidade do leite cru caprino.

\section{MATERIAL E MÉTODOS}

Realizou-se um experimento com leite caprino de rebanho proveniente de uma propriedade localizada no município de Farroupilha (RS), que possuía cerca de 800 animais das raças Saanen, Alpina, Toggenburg e Anglo-Nubiana, criados em sistema intensivo e alocados em baias coletivas, sobre cama de maravalha. Esta propriedade possuía sistema de ordenha fechado e armazenava o leite em dois tanques de resfriamento, sendo coletado semanalmente pela indústria processadora.

Em cinco visitas à propriedade foram coletadas 33 amostras de aproximadamente $900 \mathrm{~mL}$ de leite, diretamente no sistema de ordenha, em recipientes estéreis, as quais foram acondicionadas e transportadas em caixas isotérmicas ao laboratório. As amostras foram fracionadas em três partes iguais de $300 \mathrm{~mL}$, sendo a primeira (leite fresco) analisada no dia da coleta, e as demais, mantidas congelada $\left(-18^{\circ} \mathrm{C}\right)$ e refrigerada $\left(6^{\circ} \mathrm{C}\right)$ por oito dias para análise posterior (FonsECA, 2006), considerando que a recolha do leite caprino nas propriedades pelas empresas beneficiadoras ocorreu em intervalos semanais.

A qualidade físico-química foi determinada através da densidade, acidez titulável em graus Dornic (BrasiL, 2006), estabilidade ao calor e ao álcool. A estabilidade ao calor foi determinada por meio da fervura de cerca de $5 \mathrm{~mL}$ em tubo de ensaio e pela observação da formação de grumos. A prova de estabilidade ao etanol foi realizada em placa de Petri, utilizando-se $2 \mathrm{~mL}$ de leite e $2 \mathrm{~mL}$ de álcool em diferentes concentraçôes ( 50 a $70^{\circ} \mathrm{GL}$, em intervalos de $2^{\circ} \mathrm{GL}$ ). Considerou-se como nível de estabilidade a maior concentraçâo de álcool, quando o leite não apresentou coagulação (Mello et al., 2010).

De cada amostra, retirou-se uma alíquota de $50 \mathrm{~mL}$, a qual foi acondicionada em frasco próprio acrescido de soluçáo de Bromopol $^{\circledR}$. O material foi encaminhado ao Laboratório de Qualidade do Leite da Embrapa Clima Temperado, em Pelotas (RS), onde foram determinados os teores de gordura, proteína bruta, lactose e sólidos totais, através de espectrofotometria por radiação infravermelha, e contagem de células somáticas (CSS), em contador eletrônico por citometria de fluxo.

A qualidade microbiológica foi determinada pelos testes de redução de azul de metileno (Tronco, 1997), lactofermentação (FAGUNDEs, 1997) e quantificação de coliformes totais e termotolerantes (BrasiL, 2003).

Os dados de composição do leite foram avaliados por análise de variância (ANOVA) para amostras pareadas e teste de múltiplas comparaçóes de Tukey-Kramer, com erro de $0,1 \%$. As contagens de coliformes foram comparadas pela 
ANOVA para amostras pareadas (teste de Friedman) e pelo teste de Dunn, com erro de 0,1\%. Utilizou-se o programa estatístico GraphPad Instat.

\section{RESULTADOS E DISCUSSÃO}

A acidez média para as amostras frescas, refrigeradas e congeladas de leite, respectivamente, foi de $17^{\circ} \mathrm{D} ; 18^{\circ} \mathrm{D}$ e $18^{\circ} \mathrm{D}$, não sendo evidenciada diferença significativa do armazenamento sob frio no período analisado. Da mesma forma, Andrade et al. (2008) não encontraram diferença significativa na acidez do leite caprino congelado e armazenado após a pasteurização. Estudos demonstraram que o armazenamento sob frio (Silva; SANTos, 2010) e o congelamento (Pinto Júnior et al., 2012) não alteraram a acidez do leite caprino. Entretanto, de acordo com Behmer (1981), ao sair do úbere o leite é ligeiramente ácido, e tal acidez tende a aumentar ao longo do tempo, mesmo sob temperatura de conservação adequada.

Em trabalhos realizados com leite caprino, foram observadas variaçóes nos valores de acidez de 11 a $23^{\circ} \mathrm{D}$ (Ромbo; Furtado, 1978; Guimaráes et al., 1989; Prata et al., 1998; Mello et al., 2010), com médias próximas aos valores encontrados no presente trabalho, as quais se encontram dentro dos parâmetros esperados para leite de cabra ao final da lactação $\left(16\right.$ a $\left.18^{\circ} \mathrm{D}\right)$, dependendo da concentração de caseínas presente (Le Mens, 1991).

A acidez superior à normal é proveniente da acidificaçáo do leite pelo desdobramento da lactose, provocada por micro-organismos (BEHMER, 1981), destacando-se as bactérias láticas e do grupo coliformes. Além da acidificação, estas causam a produção de gás e outros efeitos indesejáveis no leite e derivados (Tronco, 1997).

A densidade das amostras frescas, refrigeradas e congeladas de leite foi, respectivamente, 1,029; 1,030 e 1,029 g/mL, demonstrando que não houve influência significativa do armazenamento sobre este parâmetro.

A densidade do leite de cabra em países europeus oscila entre 1,026 e 1,042 g/mL, dependendo da época do ano, do estado fisiológico, da raça, e se o leite é individual ou de rebanho (Le Mens, 1991). No Brasil, são descritos valores de densidade variando entre 1028,60 e 1034,0 g/L (Ромво; Furtado, 1978; Bonassi et al., 1997; Prata et al., 1998; BRASIL et al., 1999; Pereira et al., 2005).

A variabilidade da densidade do leite depende do teor de extrato seco e da concentração de matéria gorda (WALSTRA; Jeness, 1987; Le Mens, 1991).

No presente estudo, foram determinados teores de 3,34\% de gordura para as amostras frescas e refrigeradas, e 3,26\%, para as congeladas, não sendo observada diferença significativa entre eles (Tabela 1). ANDRADE et al. (2008) determinaram redução no teor de gordura em leite congelado $\left(-18^{\circ} \mathrm{C}\right)$. No Brasil, registros de teores de gordura no leite caprino têm variado de 3,25 a 4,38\% (Prata et al., 1998; Richards et al., 2001; Maraschin et al., 2004; Zanela et al., 2006; Costa et al., 2009), valores semelhantes aos encontrados neste trabalho e que estão dentro da faixa estabelecida pela legislação. Pereira et al. (2005) observaram 9,5\% de amostras de leite pasteurizado com teores de gordura inferior a 2,9\%, que é o valor estabelecido pela legislação brasileira (BRASIL, 2000).

Da mesma forma, as concentraçóes médias de lactose $(4,1 \%)$ foram iguais para todos os tratamentos, não sendo influenciadas pelo armazenamento. Valores próximos foram observados por Prata et al. (1998), em Santa Catarina, e Zanela et al. (2006) e Costa et al. (2009), no Rio Grande do Sul. Os valores mínimos de lactose (3,83\%) observados no presente estudo encontram-se abaixo do limite estabelecido pela legislação brasileira (4,3\%) (BrAsIL, 2000). Estudos apontam teores de 3,97\% de lactose em leite de cabras da raça Saanen (Vilanova et al., 2008) e 4,2\% em leite de cabras Saanen e Anglonubianas (Correa et al., 2010), sendo que 12 a 22\% das amostras apresentaram teores de lactose inferiores a $4 \%$. Pereira et al. (2005) encontraram 9,5\% das amostras com teor de lactose inferior ao recomendado pela legislaçấo.

Também quanto à concentração média de proteína observou-se que não houve influência do armazenamento sob frio, com valores médios de 3,2\%, de acordo com os parâmetros estabelecidos pela legislação (BRASIL, 2000). Também FonseCa et al. (2013) não observaram efeito do

Tabela 1. Percentual médio dos componentes do leite caprino em amostras analisadas após ordenha (fresca) e após armazenamento por oito dias sob refrigeração $\left(6^{\circ} \mathrm{C}\right)$ e congelamento $\left(-18^{\circ} \mathrm{C}\right)$.

\begin{tabular}{lcccc} 
Amostras & Gordura & Proteína & Lactose & Sólidos Totais \\
\cline { 2 - 5 } Fresca & $3,34( \pm 0,31)$ & $3,21( \pm 0,22)$ & $4,23( \pm 0,16)$ & $11,77( \pm 0,0)$ \\
\hline Refrigerada & $3,34( \pm 0,36)$ & $3,23( \pm 0,23)$ & $4,22( \pm 0,15)$ & $11,80( \pm 0,54)$ \\
\hline Congelada & $3,26( \pm 0,35)$ & $3,22( \pm 0,23)$ & $4,22( \pm 0,15)$ & $11,56( \pm 0,53)$ \\
\hline
\end{tabular}

DP: desvio-padrão. 
armazenamento na concentração de proteína. Entretanto, os autores encontraram valores de proteína $(3,0 \%)$ inferiores ao encontrado no presente estudo. Costa et al. (2009) também observaram valores de proteína $(3,15 \%)$ inferiores ao observado no presente estudo. Gomes et al. (1997) relataram que as modificaçóes físicas da proteína decorrentes do congelamento podem causar o aspecto floculado, observado após o descongelamento do leite de cabra. Entretanto, esta alteração não foi observada no presente estudo.

Ainda quanto à composição química do leite, observaram-se valores de sólidos totais semelhantes nas amostras do leite fresco e armazenado, sendo o valor médio encontrado $(11,76 \%)$ superior ao mínimo $(8,2 \%)$ estabelecido pela legislação (Brasıl, 2000). Valores semelhantes (11,9\%) foram observados em leite caprino no Rio Grande do Sul (Costa et al., 2009).

Os níveis de CCS observados em leite de cabra são de $1 \times 10^{4}$ a $6,1 \times 10^{6}$ (Vilanova et al., 2008) e 2,3 x $10^{4}$ a $9,9 \times 10^{6}$ (Correa et al., 2010). No presente estudo, foi observada redução significativa $(\mathrm{p}<0,01)$ na CCS no leite congelado (Tabela 2).

A CCS do leite é afetada principalmente pela infecção intramamária e, por ser um indicador de mastite subclínica, pode ser utilizada para quantificar as perdas de produção de leite (Coldebella et al., 2004) e como parâmetro de qualidade do produto. A secreção do leite em cabras é apócrina, o que resulta em intensa descamação do epitélio glandular e, consequentemente, no aumento da quantidade de células somáticas, gerando um padrão de CCS diferente do leite da espécie bovina (Madureira et al., 2010). Segundo PARdi et al. (1995), quando a velocidade de congelamento é lenta, há a formação de grandes cristais de gelo no interior das células, bem como o aumento da pressão osmótica e a precipitação irreversível ou desnaturação dos constituintes coloidais da célula. Isso provoca lise da membrana celular, tanto em alimentos como células somáticas. O congelamento do leite feito sob condiçóes experimentais (em freezer doméstico, que mimetiza a condição usual de produção) propicia uma taxa de congelamento lenta, o que pode explicar a destruição celular.

A estabilidade térmica é definida como o tempo necessário para originar a coagulação visível do leite em dada temperatura (Walstra; Jeness, 1987). Neste trabalho, verificou-se que a totalidade das amostras foi estável ao calor, independentemente da forma de armazenagem. Mello et al. (2010), por outro lado, observaram coagulação de 39,46\% das amostras, analisadas após refrigeração por 12 horas, sendo 32\% provenientes de cabras Saanen e 53,85\% de cabras Alpinas. Quanto ao leite bovino, a estabilidade térmica varia muito com a estação do ano (WALSTRA; JenESS, 1987) e está relacionada também à acidez do leite.

O leite se mostrou instável ao álcool nas amostras frescas, refrigeradas e congeladas a partir de $54,6^{\circ} \mathrm{GL}, 54,3^{\circ} \mathrm{GL}$ e $54,2^{\circ} \mathrm{GL}$, respectivamente. Não foi observada influência significativa do armazenamento sob frio para este parâmetro. Mello et al. (2010) verificaram estabilidade média ao álcool $52^{\circ} \mathrm{GL}$, sendo que $76,4 \%$ das amostras apresentaram estabilidade ao álcool em graduação inferior a $60^{\circ} \mathrm{GL}$. Da mesma forma, Guimarães (1993) e Silva; Santos (2010) apontaram a solução de etanol a $52-55 \%$ como sendo efetiva para fins de seleçáo de leite de cabra, pelo fato de o leite desta espécie possuir maior instabilidade ao álcool. Já Guo et al. (1998) observaram estabilidade do leite caprino ao álcool entre 40 e $44^{\circ} \mathrm{GL}$.

Quanto aos parâmetros microbiológicos, o teste de redução de azul de metileno determinou que o tempo médio para a redução foi de $5( \pm 0,24), 5( \pm 0,57)$ e 4 $( \pm 0,98)$ horas para as amostras frescas, refrigeradas e congeladas, respectivamente, não sendo evidenciada influência significativa do armazenamento sob frio. Estes resultados demonstram boa qualidade microbiológica, uma vez que o tempo de descoloração das amostras foi sempre superior a 2 horas e 30 minutos, tempo de referência para esta prova no Brasil (VIEIRA et al., 2005).

No leite proliferam numerosos micro-organismos, predominantemente bactérias que alteram a sua composição. Em geral, alteraçôes significativas são percebidas em contagens superiores a $10^{6} \mathrm{UFC} / \mathrm{mL}$ (WALSTra; JenEss, 1987). $\mathrm{Na}$ prova de lactofermentação, de acordo com o tipo de coágulo formado, pode-se inferir qual é a flora predominante na amostra analisada (BEHMER, 1981). Observou-se ocorrência de coágulo digerido, floculoso e sulcado nas amostras (Tabela 3). Embora o coágulo do tipo sulcado

Tabela 2. Valores médios, mínimos e máximos da contagem de células somáticas em leite caprino fresco e após refrigeração $\left(6^{\circ} \mathrm{C}\right)$ e congelamento $\left(-18^{\circ} \mathrm{C}\right)$, por oito dias.

\begin{tabular}{lccc} 
Amostra & Média & Mínimo & Máximo \\
\hline Fresca & $2.585 .303^{\mathrm{a}}$ & 444.000 & 4.712 .000 \\
\hline Refrigerada & $2.590 .242^{\mathrm{a}}$ & 438.000 & 4.520 .000 \\
\hline Congelada & $2.190 .455^{\mathrm{b}}$ & 388.000 & 4.590 .000 \\
\hline
\end{tabular}

Letras diferentes na mesma coluna indicam diferença estatística significativa $(p<0,01)$. 
Tabela 3. Quantificação dos diferentes tipos de coágulos em amostras de leite caprino submetidas à prova de lactofermentação após ordenha (fresca) e após armazenamento, por oito dias, sob refrigeração $\left(6^{\circ} \mathrm{C}\right)$ e congelamento $\left(-18^{\circ} \mathrm{C}\right)$.

\begin{tabular}{lccc} 
& & Amostras de leite & \\
Tipo de coágulo & Fresca & Resfriada & 12 \\
\cline { 2 - 4 } Floculoso & 12 & 11 & 11 \\
\hline Sulcado & 11 & 11 & 10 \\
\hline Digerido & 9 & 0 & 0 \\
\hline Homogêneo & 1 & 1 & 0 \\
\hline Caseoso & 0 & & 10 \\
\hline
\end{tabular}

Tabela 4. Número mais provável de coliformes totais e termotolerantes em amostras de leite caprino analisadas após ordenha (fresca) e após armazenamento, por oito dias, sob refrigeração $\left(6^{\circ} \mathrm{C}\right)$ e congelamento $\left(-18^{\circ} \mathrm{C}\right)$.

\begin{tabular}{|c|c|c|}
\hline Amostra & Coliformes totais & Coliformes termotolerantes \\
\hline Fresca & $43^{a, b}$ & $3,6^{b}$ \\
\hline Refrigerada & $43^{b}$ & $36^{a}$ \\
\hline Congelada & $93^{a}$ & $9,1^{\mathrm{b}}$ \\
\hline
\end{tabular}

Letras diferentes na mesma coluna indicam diferença estatística significativa $(p<0,01)$.

possa ocorrer em decorrência da presença de coliformes (FAGUNDES, 1997), não foi observada correlaçáo entre os tipos de coágulos e a contagem bacteriana.

O leite é um excelente substrato para o crescimento microbiano, e sua contaminação no úbere (mastite) ou após a ordenha (coleta, armazenamento, transporte, entre outros) pode regular a presença, o número e a proporção de micróbios no leite e derivados (Germano; Germano, 2008).

A quantificação (NMP) de coliformes totais e termotolerantes nas amostras de leite variaram de $<3$ (ausência de crescimento) a > $1.100 \mathrm{UFC} / \mathrm{mL}$, independentemente da forma de armazenamento. Entretanto, determinou-se contagem média de coliformes totais e termotolerantes significativamente maior $(\mathrm{p}<0,01)$ nas amostras mantidas sob refrigeração (Tabela 4). Os micro-organismos do grupo coliformes se desenvolvem e predominam em temperatura de 30 a $36^{\circ} \mathrm{C}$, podendo se desenvolver em ambientes de 20 a $45^{\circ} \mathrm{C}$. Entretanto, bactérias dos gêneros Enterobacter, Escherichia e Serratia são descritas como pertencentes ao grupo de micro-organismos psicrófilos comuns em alimentos, os quais se desenvolvem em temperatura de refrigeração (Germano; Germano, 2008).

A pesquisa de bactérias do grupo dos coliformes é importante devido à sua relaçáo com a higiene durante a produção. ANDRADE et al. (2008) encontraram apenas uma amostra de leite cru com coliformes termotolerantes $(0,4 \mathrm{NMP} / \mathrm{mL})$.

$\mathrm{O}$ volume diário de leite caprino produzido nas unidades produtivas é pequeno, o que leva as indústrias beneficiadoras a realizar coletas em intervalos até semanais. Desta forma, o leite precisa ser armazenado a baixas temperaturas para garantir sua qualidade, sendo o processo de congelamento permitido pela legislação brasileira (BRASIL, 2000) para o leite da espécie caprina nos estabelecimentos produtores.

Entretanto, é importante salientar que o armazenamento do leite congelado mantém as qualidades microbiológicas iniciais da matéria prima. Dessa forma, para garantir a qualidade do leite e derivados é indispensável que o leite seja obtido de animais saudáveis, utilizando manejo de ordenha e procedimentos de higiene baseados nos princípios de boas práticas agropecuárias.

\section{CONCLUSÕES}

$\mathrm{O}$ armazenamento a baixas temperaturas pode resultar em alteraçôes nos indicadores de qualidade do leite caprino, quantidade de micro-organismos e CCS.

\section{AGRADECIMENTOS}

À FAPERGS, pelo apoio financeiro (processo No 0619726 Edital Casadinho). 


\section{REFERÊNCIAS}

ANDRADE, P.V.D.; SOUZA, M.R.; PENNA, C.F.A.M.; FERREIRA, J.M. Características microbiológicas e físico-químicas do leite de cabra submetido à pasteurização lenta pós-envase e ao congelamento. Ciência Rural, v.38, n.5, p.1424-1430, 2008.

BEHMER, M.L.A. Tecnologia do leite. 11 a ed. São Paulo: Nobel, 1981. 322p.

BONASSI, I.A.; MARTINS, D.; ROÇA, R.O. Composição química e propriedades físico-químicas do leite de cabra. Ciência e Tecnologia de Alimentos, v.17, n.1, p.57-63, 1997.

BRASIL, L.H.A.; BONASSI, I.A.; BACCARI JUNIOR, F.; WECHSLER, F.S. Efeito da temperatura ambiental na densidade e ponto de congelamento do leite de cabra. Ciência e Tecnologia de Alimentos, v.19, n.3, p.333-337, 1999.

BRASIL. MINISTÉRIO DA AGRICULTURA E ABASTECIMENTO. Instrução Normativa n 37, de 31 de outubro de 2000. Disponível em: <http://extranet.agricultura.gov.br/sislegis-consulta/ consultarLegislacao.do?operacao=visualizar\&id $=2193>$. Acesso em: 15 fev. 2010

BRASIL. MINISTÉRIO DA AGRICULTURA, PECUÁRIA E ABASTECIMENTO. Instrução Normativa n ${ }^{\circ} 62$, de 26 de agosto de 2003. Disponível em: <http://www.agricultura.gov.br/sislegis>. Acesso em: 06 mar. 2012.

BRASIL. MINISTÉRIO DA AGRICULTURA, PECUÁRIA E ABASTECIMENTO. Instrução Normativa $n^{\circ} 68$, de 12 de dezembro de 2006. Disponível em: <http://extranet.agricultura.gov.br/ sislegis-consulta/consultarLegislacao. do?operacao=visualiza r\&id=17472 >. Acesso em: 06 mar. 2012.

COLDEBELLA, A.; MACHADO, P.F.; DEMÉTRIO, C.G.B.; RIBEIRO JÚNIOR, P.J.; MEYER, P.M.; CORASSIN, C.H.; CASSOLI, L.D. Contagem de Células Somáticas e Produção de Leite em Vacas Holandesas Confinadas. Revista Brasileira de Zootecnia, v.33, n.3, p.623-634, 2004.

CORREA, C.M.; MICHAELSEN, R.; RIBEIRO, M.E.R.; PINTO, A.T.; ZANELA, B.; SCHMIDT, V. Composição do leite e diagnóstico de mastite em caprinos. Acta Scientiae Veterinariae, v.38, n.3, p.269-274, 2010.

COSTA, M.G.; CORDEIRO, A.G.P.C.; CORDEIRO, P.R.C. Análise dos componentes do leite de cabra de rebanhos do Rio Grande do Sul. In: REUNIÃO ANUAL DA SOCIEDADE BRASILEIRA DE ZOOTECNIA, 46., 2009. Maringá. Disponível em: <http://www. sbz.org.br/reuniaoanual/anais/>. Acesso em: 28 out. 2013.

CURI, R.A.; BONASSI, I.A. Elaboração de um queijo análogo ao pecorino romano produzido com leite de cabra e coalhada congelados. Ciências Agrotécnicas, v.31, p.171-176, 2007.

EVANGELISTA, J. Tecnologia dos alimentos. Rio de Janeiro: Ateneu, 1987.652p.

FAGUNDES, C.M. Inibidores e controle de qualidade do leite. Pelotas: UFPEL, 1997. $115 p$.
FAO. Food and Agricultural Organization. Faostat. Disponível em: <http://faostat3.fao.org/faostat-gateway/go/to/search/*/E>. Acesso em: 28 out. 2013.

FONSECA, C.D.; BORDIN, K.; FERNANDES, A.M.; RODRIGUES, C.E.C.; CORASSIN, C.H.; CRUZ, A.G.; OLIVEIRA, C.A.F. Storage of refrigerated raw goat milk affecting the quality of whole milk powder. Journal of Dairy Science, v.96, n.7, p.47 16-4724, 2013.

FONSECA, C.R.; PORTO, E.; DIAS, C.T.S.; SUSIN, I. Qualidade do leite de cabra in natura e do produto pasteurizado armazenados por diferentes períodos. Ciência e Tecnologia dos Alimentos, v.26, n.4, p.944-949, 2006.

GERMANO, P.M.L.; GERMANO, M.I.S. Higiene e vigilância sanitária de alimentos: qualidade das matérias-primas, doenças transmitidas por alimentos, treinamento de recursos humanos. $3^{\mathrm{a}} \mathrm{ed}$. Barueri: Manole, 2008. 986p.

GOMES, M.I.F.V.; BONASSI, I.A.; ROÇA, R.O. Chemical, microbiological and sensorial characteristics of frozen goat milk. Ciência $e$ Tecnologia de Alimentos, v.17, n.2, p.111-114, 1997.

GUIMARÃES, M.P.M.P. Avaliação da estabilidade físico química do leite caprino congelado durante a estocagem comercial. 1993. 73 f. Dissertação (Mestrado) - Universidade Federal de Minas Gerais, Belo Horizonte, 1993.

GUIMARÃES, M.P.M.P.; CLEMENTE, W.T.; SANTOS, E.C.; RODRIGUES, R. Caracterização de alguns componentes celulares e físicoquímicos do leite de cabra para diagnóstico de mamite caprina. Arquivo Brasileiro de Medicina Veterinária e Zootecnia, v.4 1, n.2, p.129-142, 1989.

GUO, M.R.; WANG, S.; L. QUI, J.; JIN, L.; KINDSTEDT, P.S. Ethanol Stability of Goat's Milk. The International Dairy Journal, v.8, n. 1, p.57-60, 1998 .

IBGE. INSTITUTO BRASILEIRO DE GEOGRAFIA E ESTATÍSTICA. Censo agropecuário 2006. Disponível em: <http://www.sidra. ibge.gov.br/bda/pesquisas/ca/default.asp\#8>. Acesso em: 20 out. 2009.

LE MENS, P. Propriedades físico-químicas, nutricionales y químicas. In: LUQUET, F.M.; KEILLING, J.; WILDE, R. Leche y Productos lácteos: vaca, oveja y cabra. Zaragoza: Acribia, 1991. p.343-359.

MADALENA, F.E. Valores Econômicos para a Seleção de Gordura e Proteína do Leite. Revista Brasileira de Zootecnia, v.29, n.3, p.678-684, 2000 .

MADUREIRA, K.M..; GOMES, V.; CASTRO, R.S.; KITAMURA, S.S.; ARAÚJO, W.P. Análise das metodologias diretas e indiretas para a contagem de células somáticas no leite de cabras hígidas. Pesquisa Veterinária Braseileira, v.30, n.4, p.311-316, 2010.

MARASCHIN, F.L.; PINTO, A.T.; SCHMIDT, V. Presença de coliformes e parâmetros físico-químicos do leite de cabra integral pasteurizado de um laticínio sob inspeção estadual, no Rio Grande do Sul. Pesquisa Agropecuária Gaúcha, v.10, n. 1-2, p.73-77, 2004. 
MELLO, F.A.; PINTO, A.T.; ZANELA, M.B.; SCHMIDT, V. Estabilidade térmica e ao álcool do leite de cabras Saanen e Alpina. Acta Scientiae Veterinariae, v.38, n.2, p.165-169, 2010.

PARDI, M.C.; SANTOS, I.F.; SOUZA, E.R.; PARDI, H.S. Ciência, higiene e tecnologia da carne, v.1. Goiânia: EDUFF/CEGRAF, 1995. 586p.

PEREIRA, R.A.G.; QUEIROGA, R.C.R.E.; VIANNA, R.P.T.; OLIVEIRA, M.E.G. Qualidade química e física do leite de cabra distribuído no Programa Social "Pacto Novo Cariri" no Estado da Paraíba. Revista do Instituto Adolfo Lutz, v.64, n.2, p.205-21 1, 2005.

PHILPOT, W.N. Importância da Contagem de Células Somáticas e Outros Fatores que Afetam a Qualidade do Leite. In: SIMPÓSIO INTERNACIONAL SOBRE QUALIDADE DO LEITE, 1., 1998. Anais. Curitiba. p.28-35.

PINTO JÚNIOR, W.R.; FERRÃO, S.P.B.; RODRIGUES, F.L.; FERNANDES, S.A.A.; BONOMO, P. Efeito do congelamento sobre os parâmetros físico-químicos do leite de cabras da raça Saanen. Revista Caatinga, v.25, n.3, p. $110-117,2012$.

PIRISI, A.; LAURENT, A.; DUBEUF, J.P. Basic and incentive payment for goat and sheep milk in relation to quality. Small Ruminant Research, v.68, n.1-2, p.167-178, 2007.

POMBO, W.A.F.; FURTADO, M.M. Fabricação do queijo tipo Chabichou. I. Algumas características físico-químicas do leite de cabra da Zona da Mata Mineira. Revista do Instituto de Laticínios Candido Tostes, v.33, n.200, p.3-11, 1978.

PRATA, L.F.; RIBEIRO, A.C.; REZENDE, K.T.; CARVALHO, M.R.B.; RIBEIRO, D.A.; COSTA, R.G. Composição, perfil nitrogenado e características do leite caprino (Saanen). região Sudeste, Brasil. Ciência e Tecnologia de Alimentos, v.18, n.4, p.428-432, 1998.
RICHARDS, N.S.P.S.; PINTO, A.T.; SILVA, M.E.; CARDOSO, V.C. Avaliação físico-química da qualidade do leite de cabra pasteurizado comercializado na Grande Porto Alegre, RS. Revista do Instituto de Laticínios Cândido Tostes, v.56, n.321, p.217-220, 2001.

SILVA, S.P.; SANTOS, M.E.R. Testes de qualidade no leite caprino em função do tempo de armazenamento no tanque de refrigeração. Enciclopédia Biosfera, v.6, n.10, 2010.

TRONCO, V.M. Manual para inspeção da qualidade do leite. Santa Maria: UFSM, 1997. 166p.

VIEIRA, L.C.; KANEYOSHI, C.M.; FREITAS, H. Criação de Gado Leiteiro na Zona Bragantina: Qualidade do leite. Sistemas de Produção, n.2, 2005. (Edição EletrônicaEmbrapa Amazônia Oriental). Disponível em: <http:// sistemasdeproducao.cnptia.embrapa.br/FontesHTML/Leite/ GadoLeiteiroZonaBragantina/paginas/qualidade.htm>. Acesso em: 22 maio 2012.

VILANOVA, M.S.; GONÇALVES, M.; OSORIO, M.T.M.; ESTEVES, R.; SCHMIDT, V. Aspectos sanitários do úbere e composição química do leite de cabras Saanen. Acta Scientiae Veterinariae, v.36, n.3, p.235-240, 2008.

WALSTRA, P.; JENESS, R. Quimica y física lactologica. Zaragoza: Acribia, 1987. 423p.

ZANELA, M.B.; SCHMIDT, V.; PINTO, A.T.; MACHADO, M.; SOUZA, P.A.S.C.; SILVA, F.F.P.; REICHERT, S.; RIBEIRO, M.E.R. Produção e composição química do leite de cabra na Expointer 2006 - RS. In: CONGRESSO BRASILEIRO DA QUALIDADE DO LEITE, 2., 2006, Goiânia. Resumo 34. Disponível em: <http://www.terraviva.com.br/IICBQL/p034.pdf>. Acesso em: 24 jun. 2011. 